\title{
Studies on the Gastrointestinal Hormones. V.1,2) Distribution of Gastric Secretory Inhibiting Substance in Whale Gastrointestinal Mucosa
}

\author{
Hisatoshi Kabeno, Teturo Honda, Yasuaki Kobayashi ${ }^{3 a}$ ) \\ and Toshiro Murata ${ }^{3 b)}$ \\ Research Laboratory, Nissui Pharmaceutical Co., Ltd. ${ }^{30)}$ and \\ Shizuoka College of Pharmacy ${ }^{3 b}$ )
}

(Received February 12, 1971)

Gastrone, ${ }^{4)}$ enterogastrone, ${ }^{5)}$ and secretin ${ }^{6)}$ have been known as the substances contained in mammalian digestive tract and having inhibitory action on the secretion of gastric juice.

A glycoprotein fraction, designated as $\mathrm{E}$ fraction, has been isolated from the gastric mucosal layer of finback whale and found to have a marked inhibitory action on the gastric juice secretion by the authors.1)

In order to clarify the mechanism of the inhibitory action on the gastric juice secretion, the distribution of the substance in the mucosal layer of gastrointestinal tissues from the 3rd stomach to small intestine of sperm whale was studied in this paper.

\section{Experimental}

Material-The sperm whale (Physeter catodon L.) used, $15 \mathrm{~m}$ in length male, was supplied by the Onagawa Plant of the Nippon Suisan Co. The digestive tract was fractionated as shown in Fig. 1. After washing thoroughly with water, the mucosal layer was separated from muscular layer.

Preparation of Crude Extracts-The mucosal layer was cut into small pieces and boiled with 2 volumes of water for $30 \mathrm{~min}$.

After cooling, the water extract was decanted, and the residue was boiled again with 2 volumes water for $30 \mathrm{~min}$.

Both extracts were combined and allowed to stand overnight in a cold room $\left(5^{\circ}\right)$. Then the extracts were filtered.

A solution of $200 \mathrm{~g}$ of benzoic acid per $\mathrm{kg}$ of mucosal layer dissolved in $400 \mathrm{ml}$ of acetone was added to the filtrate with stiring, and the mixture was stirred for $2 \mathrm{hr}$. The mixture was again allowed to stand overnight in a cold room.

The precipitate thus formed was separated by centrifugation, and washed three times with $300 \mathrm{ml}$ of acetone and twice with $300 \mathrm{ml}$ of ether. The washed precipitate was dehydrated over $\mathrm{P}_{2} \mathrm{O}_{5}$ in vacuo for $24 \mathrm{hr}$ and used as the crude extract.

Gel Filtration-A solution of $500 \mathrm{mg}$ of the crude extract dissolved in $0.15 \mathrm{M} \mathrm{NaCl}$ was passed through a column $(2.0 \times 75 \mathrm{~cm})$ of Sephadex G-100 gel

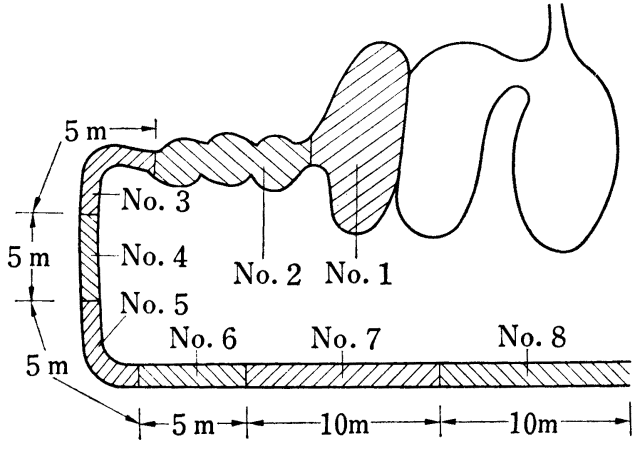

Fig. 1. Gastrointestinal Tract of Physeter catodon $L$.

No. 1: the 3rd stomach No. 2: the 4th stomach No. 3-8: small intestinal tract

1) Part IV: H. Kabeno, T. Honda, S. Kondo, K. Tachibana, Y. Kobayashi and T. Murata, Yakugaku Zasshi, 90, $576(1970)$.

2) This work was presented at the 89th Annual Meeting of the Pharmaceutical Society of Japan, Nagoya, April 1969.

3) Location: a) 1805, Inari-cho, Soka-shi, Saitama-ken; b) 160 Oshika, Shizuoka.

4) R. Fiasse, C.F. Code and G.B.J. Glass, Gastroenterology, 54, 1018 (1968).

5) T. Kosaka and R.K.S. Lim, Proc. Soc. Exp. Biol. \& Med., 27, 890 (1930).

6) W.M. Bayliss and E.H. Starling, J. Physiol., 28, 325 (1902). 
and the column was eluted with $0.15 \mathrm{M} \mathrm{NaCl}$. Each fraction was desalted by passing through a column $(2.0 \times 75 \mathrm{~cm})$ of Sephadex G-10 gel and then was lyophilized.

Analysis of Constitutional Components-Protein was determined by the method of Lowry, et al. ${ }^{7)}$ using serum albumine (Cohn Fraction V) as a standard; in some preparations, nitrogen content was measured by means of the semimicro-Kjeldahl method. Hexose was determined by Phenol-sulfuric acid method of Sato. ${ }^{8)}$ Hexosamine was assayed according to the method of Kobayashi.9) Ultraviolet (UV) absorption spectra of each fraction were recorded at $280 \mathrm{~m} \mu$ on a Hitachi UV Spectrophotometer.

Method for Measuring the Inhibitory Action on Gastric Juice Secretion-Shay's method ${ }^{10}$ ) of using pylorus-ligated rat was employed to male rats of Donryu strain, weighing $180-200 \mathrm{~g}$. They were fasted for $48 \mathrm{hr}$ and abdomen was incised $1 \mathrm{~cm}$ below the xiphoid process and the pylorus was ligated under ether anesthesia. Then the test material dissolved in $0.5 \mathrm{ml}$ of saline was injected from tail vein and stomach was taken out after $4 \mathrm{hr}$.

The gastric juice accumulated was separated by centrifugation. The volume of supernatant was measured, and free acidity was titrated with $0.1 \mathrm{~N}$ sodium hydroxide using $p$-dimethylaminoazobenzene as indicator. The control animals given physiological saline were also treated in the same way, and inhibitory activity was expressed as percentage of the control output of gastic secretion.

\section{Result and Discussion}

Yields and antisecretory activities of the crude extract obtained by benzoic acid precipitation are shown in Table I.

TABle I. Yields and Biological Activities of Crude Substances

\begin{tabular}{ccccc}
\hline \hline Fraction No. & $\begin{array}{c}\text { Mucosal layer } \\
(\mathrm{g})\end{array}$ & $\begin{array}{c}\text { Yield } \\
(\mathrm{g})\end{array}$ & $\begin{array}{c}\text { Yield/Mucosal } \\
\text { layer } \\
(\mathrm{g} / \mathrm{kg})\end{array}$ & $\begin{array}{c}\text { Biological } \\
\left.\text { activity }{ }^{a}\right) \\
(\%)\end{array}$ \\
\hline 1 & 1250 & 10.00 & 8.01 & 65.1 \\
2 & 1250 & 5.56 & 4.45 & 37.6 \\
3 & 1650 & 11.00 & 6.67 & 86.3 \\
4 & 1450 & 9.16 & 6.32 & 83.5 \\
5 & 1650 & 6.00 & 3.63 & 87.8 \\
6 & 1750 & 6.52 & 3.73 & 44.9 \\
7 & 2750 & 8.02 & 2.92 & 7.5 \\
8 & 3600 & 7.98 & 2.22 & 7.2 \\
\hline
\end{tabular}

a) Biological activity was shown by the inhibition $\%$ of free acid secretion by using Shay rat. Samples were injected intravenously with the dose of $20 \mathrm{mg} / \mathrm{kg}$.

Both the yield and activity were shown to be greater in the 3rd stomach (No.1) than in the 4th stomach (No. 2).

From the data shown in Table I, the yield of the active substance in No. 1 is 4 times of that in No. 2. The yields of this substance in the mucosal layer of small intestine was shown to be greater in the upper $10 \mathrm{~m}$ (No. 3 and No. 4) than the other parts, but biological activity was practically the same in No. 3, 4 and 5. Both the yield and biological activity were smaller in No. 6 and others. Gel filtration of the crude extracts obtained from 1,2, 3 and 7 through Sephadex G-100 showed, as indicated in Fig. 2, that the UV absorptions of elution pattern were seemed to be similar in all these fractions, and the biological activity was present in the first peak (G-1).

Yields and activities against gastric secretion of the first fractions are shown in Table II.

Yields of 1-G-1 (23.3\%) and 3-G-1 (16.6\%) were about twice of those in 2-G-1 $(12.1 \%)$ and $7-\mathrm{G}-1(8.6 \%)$ respectively, and it was shown that yields were seem to be paralleled to the

7) O.H. Lory, N.J. Rosebrough, A.L. Farr and R. J. Randall, J. Biol. Chem., 193, 265 (1951).

8) T. Sato, Seikagaku, 33, 42 (1958).

9) M. Kobayashi, "Roshi Zon Denkieido No Jissai, "Nankodo, 1960, p.202.

10) H. Shay, S.A. Komarov, R.F. Fels, D. Meranze, M. Cruenttein and H. Siplet, Gastroenterology, 5, 43 (1945). 

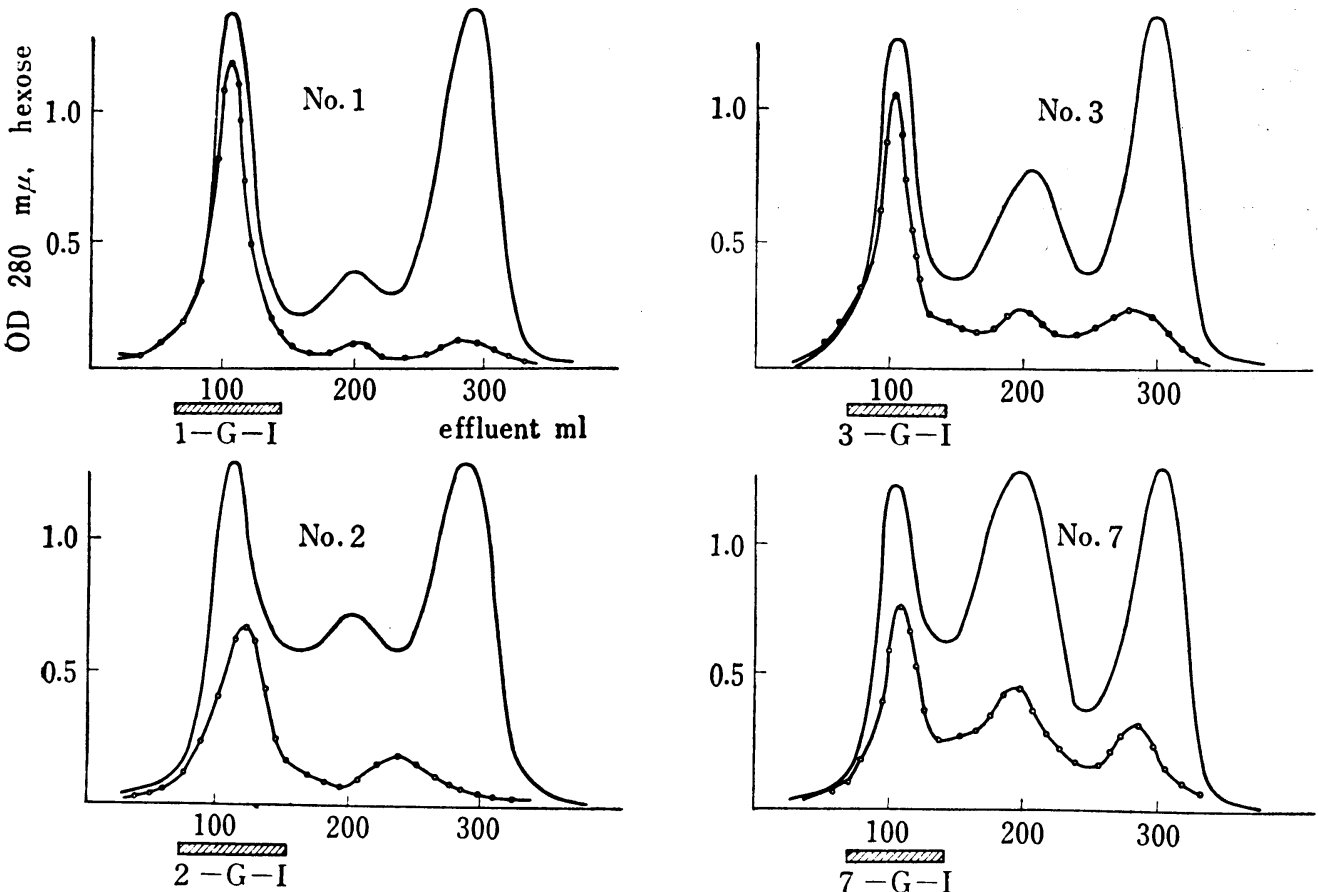

Fig. 2. Elution from Sephadex G-100

The crude substances $(500 \mathrm{mg})$ dissolved in $0.15 \mathrm{x} \mathrm{NaCl}(5 \mathrm{ml})$ were applied to Sephadex G-100 column $(2.0 \times 75 \mathrm{~cm})$ Each sample was monitored at $280 \mathrm{~m} \mu$ for protein concentration; aliquots $(0.5 \mathrm{ml})$ were taken from each sample tube

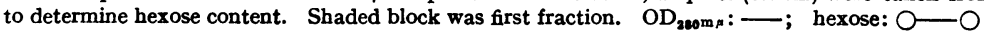

TABLE II. Yields and Biological Activities of the First Fractions obtained by Gel Filtration

\begin{tabular}{|c|c|c|c|}
\hline & \multicolumn{2}{|c|}{ Yields of the first fractions } & \multirow{2}{*}{$\begin{array}{c}\left.\text { Biological activity }{ }^{a}\right) \\
(\%)\end{array}$} \\
\hline & (mg/crude extract $500 \mathrm{mg}$ ) & $(\%)$ & \\
\hline 1-G-1 & 116.5 & 23.3 & 69.5 \\
\hline 2-G-1 & 60.5 & 12.1 & 71.4 \\
\hline $3-\mathrm{G}-1$ & 83.0 & 16.6 & 66.9 \\
\hline $7-G-1$ & 43.0 & 8.6 & 66.0 \\
\hline
\end{tabular}

a) Biological activity was shown by the inhibition $\%$ of free acid secretion by using Shay rat. Samples were injected intravenously with the dose of $1.0 \mathrm{mg} / \mathrm{kg}$.

TABLE III. Chemical Composition of First Fractions obtained by Gel Filtration

\begin{tabular}{lrrrr}
\hline Fraction & $1-G-1$ & $2-G-1$ & $3-G-1$ & $7-G-1$ \\
\hline Nitrogen (\%) & 15.5 & 14.8 & 15.3 & 15.7 \\
Protein (\%) & 70.0 & 68.2 & 72.8 & 71.5 \\
Hexose (\%) & 2.8 & 4.8 & 3.5 & 4.9 \\
Hexosamine (\%) & 10.9 & 11.6 & 10.8 & 12.9 \\
\hline
\end{tabular}

biological activities of crude extract. Chemical composition of these high-molecular fraction is summarized in Table III, which indicates that their chemical compositions are similar.

Those were all glycoprotein containing about $70 \%$ of protein, $5 \%$ of hexose, and $10 \%$ of hexosamine. 
Glass and others ${ }^{4)}$ submitted the lyophilized substance obtained from human gastric juice to gel filtration and obtained two kinds of substances which inhibited gastric juice secretion.

The high-molecular fraction of them is thought to be same as the fraction obtained by the authors both in the chemical composition and the biological activity.

The inhibitory substances obtained from mucosal layers of stomach and small intestine are shown to be similar either in the chemical composition or the biological activity. And a main component of them is assumed to be a glycoprotein for the present.

Acknowlegement Thanks are due to the Onagawa Plant of the Nippon Suisan Co. for the supply of the samples used in the present work, and to Messra. Koji Namiki and Shigetoshi Okado of this laboratory for technical assistance. 